\title{
An Experimentally Validated Analytical Model for Aerosol Number Concentration Reduction in Classrooms
}

\author{
Qingfeng Cao ${ }^{1}$, Thomas H. Kuehn ${ }^{1}$, Seong Chan Kim ${ }^{1}$, Qisheng $\mathrm{Ou}^{1}$, \\ Chenxing Pei ${ }^{1}$, David Y.H. Pui ${ }^{1,2^{*}}$ \\ ${ }^{1}$ Department of Mechanical Engineering, University of Minnesota, 111 Church Street SE, \\ Minneapolis, Minnesota 55455, USA \\ ${ }^{2}$ School of Science and Engineering, The Chinese University of Hong Kong, Shenzhen, \\ Guangdong 518172, China
}

\section{ABSTRACT}

To predict the aerosol number concentration decay in modern classrooms, this study derived an analytical model that addresses various indoor factors, viz., the filtration efficiency of air ventilation systems, effects of indoor air cleaners, particle deposition on walls, and particle emission from occupants. We also conducted experimental measurements to determine the wall-loss coefficient and the occupants' particle generation rate, and the modeling results agreed with the experimental data reasonably well. Additionally, we investigated the behavior of the particle concentration decay in different ventilation scenarios. The model has been incorporated into web-based software that is freely available to the public.

Keywords: Analytical model, Aerosol concentration, Classrooms, Ventilation system, Indoor air quality, COVID-19

\section{INTRODUCTION}

\section{OPEN ACCESS}

Received: February 22, 2021

Revised: May 11, 2021

Accepted: May 15, 2021

\section{${ }^{*}$ Corresponding Author: \\ dyhpui@umn.edu}

\section{Publisher:}

Taiwan Association for Aerosol Research

ISSN: $1680-8584$ print

ISSN: 2071-1409 online

(c) Copyright: The Author(s). This is an open access article distributed under the terms of the Creative Commons Attribution License (CC BY 4.0), which permits unrestricted use, distribution, and reproduction in any medium, provided the original author and source are cited.
The coronavirus 2019 (COVID-19) pandemic has resulted in severe disruption to the economy and social activities and caused coronavirus disease for millions of patients worldwide (Bartik et al., 2020; Donthu and Gustafsson, 2020; Mehta et al., 2020; Nicola et al., 2020; Shereen et al., 2020; Zheng et al., 2020). With schools and universities reopening in September 2020 in the United States, the potential airborne transmission of COVID-19 in classrooms has raised significant concerns regarding the safety of students and teachers during classes. Studies have found that the transmission of COVID-19 has a relation to indoor ambient aerosols (Amirav and Newhouse, 2020; Asadi et al., 2020; Mehmood et al., 2020; van Doremalen et al., 2020). Therefore, ventilation systems play a key role in controlling coronavirus spreading in the classrooms, dental clinics, hospitals, etc. by keeping the indoor infectious virus aerosol concentration at a minimal level. This study aims to develop an analytical model for the particle number concentration decay under different operational conditions of ventilation systems in modern classrooms, which will be beneficial for minimizing the indoor airborne transmission of COVID-19.

Many researchers have conducted investigations on indoor air quality in classrooms. A major group of studies were focused on the indoor-outdoor correlations of particle number concentrations for classrooms under different ventilation situations (Tippayawong and Khuntong, 2007; Guo et al., 2008; Mullen et al., 2011; Fuoco et al., 2015; Ren et al., 2020). They found that air exchange rate and outdoor contaminant concentrations have a significant impact on classroom particle concentrations. In addition, the effect of ventilations systems on indoor air quality was evaluated through numerous experimental and numerical investigations, and different ventilation strategies were studied and suggested for better controlling the indoor concentration levels (Holmberg and 
Chen, 2003; Howard-Reed et al., 2003; Park et al., 2008; Tian et al., 2009; Stabile et al., 2016; Johnson et al., 2018; Stabile et al., 2019). Weichenthal et al. (2008) characterized the ultrafine particle levels in Canadian classrooms and developed a model to predict the ultrafine particle concentrations based on the weather conditions, outdoor particle concentrations and classroom conditions. Generation rates from diverse sources and removal rates by deposition and air exchange processes of ultrafine particles in classrooms were quantified by Laiman et al. (2014). Fazli et al. (2019) evaluated the size-resolved removal efficiency of various new commercially available HVAC filters for ultrafine particles, which can be applied in the ventilation systems of schools and universities. Investigators have also previously conducted size-resolved concentration measurements on biological aerosols in classrooms under occupied and vacant conditions to study the influence of occupant emissions on indoor air quality (Qian et al., 2012; Bhangar et al., 2014). The impact of occupants' activities on aerosol emissions and source of contaminants in classrooms were also examined by several experimental researchers (Alshitawi and Awbi, 2011; Bennett et al., 2019; Kim et al., 2019).

Over the years, various analytical and numerical models have been developed for the purpose of predicting the indoor air quality under different situations. Well-mixed models have been around for several decades, and local mean age and ventilation effectiveness were introduced in the 1970s to expand beyond the limitation of assuming perfect mixing (Kuehn et al., 1998). Nazaroff and Cass (1989) presented a mathematical framework for particle concentrations in indoor air, which considered the effects of ventilation, filtration, surface deposition, emission, and coagulation. The study by Pui et al. (2008) indicated that airborne nanoparticle concentrations were significantly diminished by recirculation air filtration, and an analytical model was developed to account for the particle concentration change in a closed space. Adeniran et al. (2019) performed analytical modeling for human exposure to aerosols as a function of time and distance, which describes point source dispersion and concentration decay that resulted from air exchange rate and particle deposition. Ganesh et al. (2019) developed an analytical model to predict the concentration of different kinds of indoor pollutants, which takes contaminants from an Air Handling Unit (AHU) and indoor emission sources into consideration. On the other hand, researchers have carried out numerical simulations by using computational fluid dynamics approaches to explore the physics of particle dispersion, deposition, transportation, emission, and interactions with occupants and indoor airflow fields (Holmberg and Li, 1998; Sajjadi et al., 2017; Liu et al., 2019; Nsir et al., 2019; Borro et al., 2020; Mutlu, 2020; Vuorinen et al., 2020). With the drastic advancement in the computer-science-related fields in recent years, techniques such as artificial neural network and machine learning have also been applied to predict indoor air quality (Gheziel et al., 2017; Wei et al., 2019). Nowadays, a modern classroom can be serviced by both an AHU and a Fan Coil Unit (FCU) with Indoor Air Cleaners (IACS) sometimes applied to control the indoor air quality as well. Nevertheless, there has not been a comprehensive analytical model that includes the particulate filtration efficiencies of all these modern ventilation systems and indoor air cleaners together with other effects including particle absorption on walls and particle emission from occupants.

In this paper, the derivation of the analytical model based on modern configurations of ventilation systems for classrooms is first presented, followed by introducing the method of determining the empirical parameters for the wall-loss coefficient and particle generation rate per occupant. Comparison between the analytical model and experimental data is then analyzed. In "Results," scenarios of indoor particle concentration decay with different ventilation conditions are presented and discussed.

\section{DERIVATION OF THE ANALYTICAL MODEL}

Fig. 1 presents the schematic diagram of the flow system in a classroom studied at the University of Minnesota. The ventilation system is composed of an AHU and an FCU, which are devices to regulate and circulate air as part of the heating, ventilating, and air-conditioning (HVAC) system for a modern classroom. The AHU introduces clean air into the classroom by blowing the outdoor ambient air through its filters, while the FCU functions by recirculating the room air through its filtration system. IACs have also been considered in the derivation. If we assume that the room air is perfectly mixed at all times, the governing equation describing the rate of indoor particle 


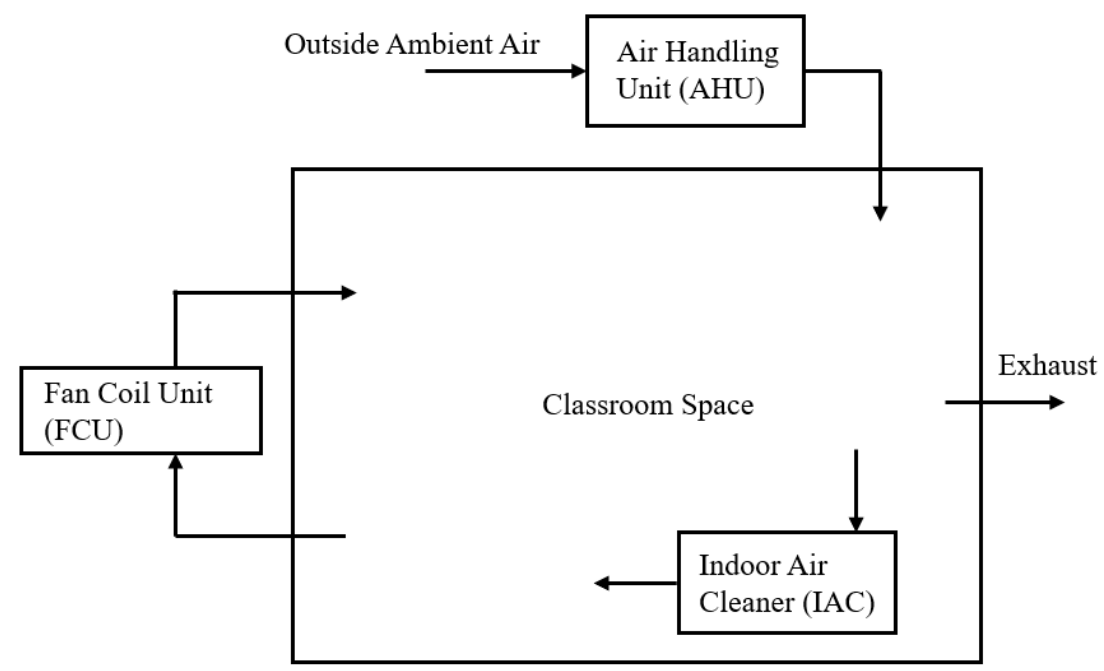

Fig. 1. A schematic diagram of the flow system in the studied classroom.

number change with time can be written as:

$V \frac{d N_{d p}(t)}{d t}=Q_{A H U}\left(1-\eta_{A H U, d p}\right) N_{a, d p}-\left(Q_{A H U}+\eta_{F C U, d p} Q_{F C U}+\eta_{I A C, d p} Q_{I A C}+A_{s} k_{w, d p}\right) N_{d p}(t)+S_{d p}$

where $V$ is the total volume of the classroom, $t$ is time, and $Q_{A H U}, Q_{F C U}$, and $Q_{I A C}$ represent the airflow rates of the AHU, FCU, and IAC, respectively. The particulate filtration efficiencies of these three systems are functions of particle size and are designated as $\eta_{\mathrm{AHU}, \mathrm{dp}}, \eta_{\mathrm{FCU}} \mathrm{dp}$, and $\eta_{\mathrm{IAC}, \mathrm{dp}}$, respectively. The number concentration of a specific particle size in the room is given as $N_{\mathrm{dp}}$ and the outdoor ambient concentration by $N_{\mathrm{a}, \mathrm{dp}}$. The indoor particle emission rate is given as $S_{\mathrm{dp}}$, with $A_{s}$ and $k_{\mathrm{w}, \mathrm{dp}}$ representing the internal surface area of the classroom and the wall-loss coefficient, respectively.

Eq. (1) is valid for a specific particle size. However, we are interested in results that encompass a range of sizes. Each term in Eq. (1) is integrated over a particle size range, $d p=m-n$, that results in the following equation:

$V \frac{d N(t)}{d t}=Q_{A H U}\left(1-\eta_{A H U}\right) N_{a}-\left(Q_{A H U}+\eta_{F C U} Q_{F C U}+\eta_{I A C} Q_{I A C}+A_{s} k_{w}\right) N(t)+S$

where the terms are no longer directly functions of particle size but depend on the particle size range selected for the integration. The particle size limits used here are $2.5 \mathrm{~nm}$ and $2 \mu \mathrm{m}$, which correspond to the range of the measuring instruments used in the corresponding experiments.

To obtain an analytical solution of Eq. (2), we first need to rewrite the equation into the following formats of:

$$
\frac{1}{\left[N(t)-\frac{S+Q_{A H U}\left(1-\eta_{A H U}\right) N_{a}}{Q_{A H U}+\eta_{F C U} Q_{F C U}+\eta_{I A C} Q_{I A C}+A_{s} k_{w}}\right]} \cdot \frac{d N(t)}{d t}=-\frac{Q_{A H U}+\eta_{F C U} Q_{F C U}+\eta_{I A C} Q_{I A C}+A_{s} k_{w}}{V}
$$

and:

$$
d\left\{\ln \left[N(t)-\frac{S+Q_{A H U}\left(1-\eta_{A H U}\right) N_{a}}{Q_{A H U}+\eta_{F C U} Q_{F C U}+\eta_{I A C} Q_{I A C}+A_{s} k_{w}}\right]\right\}=-\frac{Q_{A H U}+\eta_{F C U} Q_{F C U}+\eta_{I A C} Q_{I A C}+A_{s} k_{w}}{V} \cdot d t
$$

By integrating both sides of Eq. (4), the following equation can be obtained: 


$$
\ln \left[N(t)-\frac{s+Q_{A H U}\left(1-\eta_{A H U}\right) N_{a}}{Q_{A H U}+\eta_{F C U} Q_{F C U}+\eta_{I A C} Q_{I A C}+A_{s} k_{w}}\right]=-\frac{Q_{A H U}+\eta_{F C U} Q_{F C U}+\eta_{I A C} Q_{I A C}+A_{s} k_{w}}{V} \cdot t+M
$$

where $M$ is the coefficient generated during the integration. Eq. (5) can be further rewritten as:

$$
N(t)=a \cdot e^{\left(-\frac{Q_{A H U}+\eta_{F C U} Q_{F C U}+\eta_{I A C} Q_{A A C}+A_{s} k_{W}}{V}\right) \cdot t}+\frac{S+Q_{A H U}\left(1-\eta_{A H U}\right) N_{a}}{Q_{A H U}+\eta_{F C U} Q_{F C U}+\eta_{I A C} Q_{I A C}+A_{s} k_{W}}
$$

where $a$ is a coefficient equal to $e^{M}$. We assume that initially the classroom is well mixed with a particle number concentration of $N_{0}$. This initial condition is applied to Eq. (6) so that we are able to find the coefficient of $a$ :

$$
a=N_{0}-\frac{S+Q_{A H U}\left(1-\eta_{A H U}\right) N_{a}}{Q_{A H U}+\eta_{F C U} Q_{F C U}+\eta_{I A C} Q_{I A C}+A_{s} k_{w}}
$$

By substituting Eq. (7) into Eq. (6), the final form of the analytical solution of Eq. (2) is written as:

$$
\begin{aligned}
N(t) & =\left(N_{0}-\frac{s+Q_{A H U}\left(1-\eta_{A H U}\right) N_{a}}{Q_{A H U}+\eta_{F C U} Q_{F C U}+\eta_{I A C} Q_{I A C}+A_{s} k_{w}}\right) \cdot e^{\left(-\frac{Q_{A H U}+\eta_{F C U} Q_{F C U}+\eta_{I A C} Q_{A C C}+A_{S} k_{W}}{V}\right) \cdot t} \\
& +\frac{S+Q_{A H U}\left(1-\eta_{A H U}\right) N_{a}}{Q_{A H U}+\eta_{F C U} Q_{F C U}+\eta_{I A C} Q_{I A C}+A_{s} k_{w}}
\end{aligned}
$$

The above equation describes the particle number concentration change as a function of time. This equation can be applied to any specific airborne contaminant, including gases.

\section{DETERMINATION OF THE WALL-LOSS COEFFICIENT AND OCCUPANTS' PARTICLE GENERATION RATE}

To apply Eq. (8), the empirical parameter, the wall-loss coefficient, $k_{w}$, should be determined first. This parameter accounts for the absorption effect of walls on indoor contaminants in the classroom (Crump and Seinfeld, 1981; Crump et al., 1983; Fotou and Pratsinis, 1993). To obtain $k_{w}$, experimental measurements were carried out by shutting off all the air-cleaning devices, including the AHU, FCU and IAC, so that a natural decay of the indoor particle concentration was achieved. A classroom on the fourth floor of the Department of Mechanical Engineering at the University of Minnesota was selected for the experiments, which has dimensions of $2.65 \mathrm{~m}$, $10.25 \mathrm{~m}$, and $6.83 \mathrm{~m}$ in height, length, and width, respectively. Thus, the total volume, $V$, and internal surface area, $A_{s}$, were calculated to be $185.80 \mathrm{~m}^{3}$ and $230.65 \mathrm{~m}^{2}$, respectively. $\mathrm{NaCl}$ particles were generated by an atomizer with a $1 \%$ solution to fill the room with an initial particle concentration of $23,500 \mathrm{\#} \mathrm{cm}^{-3}$, after which the atomizer was turned off and the particle concentration was allowed to decay naturally. The decreasing concentration was monitored by a condensation particle counter (CPC Model 3756; TSI Inc.), which is able to count ultrafine particles with a size range of $2.5 \mathrm{~nm}-2 \mu \mathrm{m}$, over the next $60-\mathrm{min}$ period. As shown by the dotted curve in Fig. 2, the particle concentration decreased by $48 \%$ in $1 \mathrm{~h}$. By fitting the measurement data with Eq. (8), the wall-loss coefficient, $k_{\mathrm{w}}$, was found to be $1.71 \times 10^{-4} \mathrm{~m} \mathrm{~s}^{-1}$. The fitted curve is presented in black in the figure, with an $\mathrm{R}^{2}$ value equal to 0.940 . Note that the classroom used for the experiment was not empty, but contained several tables and chairs, which added additional surface area for particle deposition. It would be difficult for the model to account for the additional surface area precisely due to indoor furniture and furniture settings in different classrooms could vary. However, the authors believe that the present results are valid for typical classroom settings. The effect of furniture surface area on indoor particle deposition is an interesting topic for a future study. 


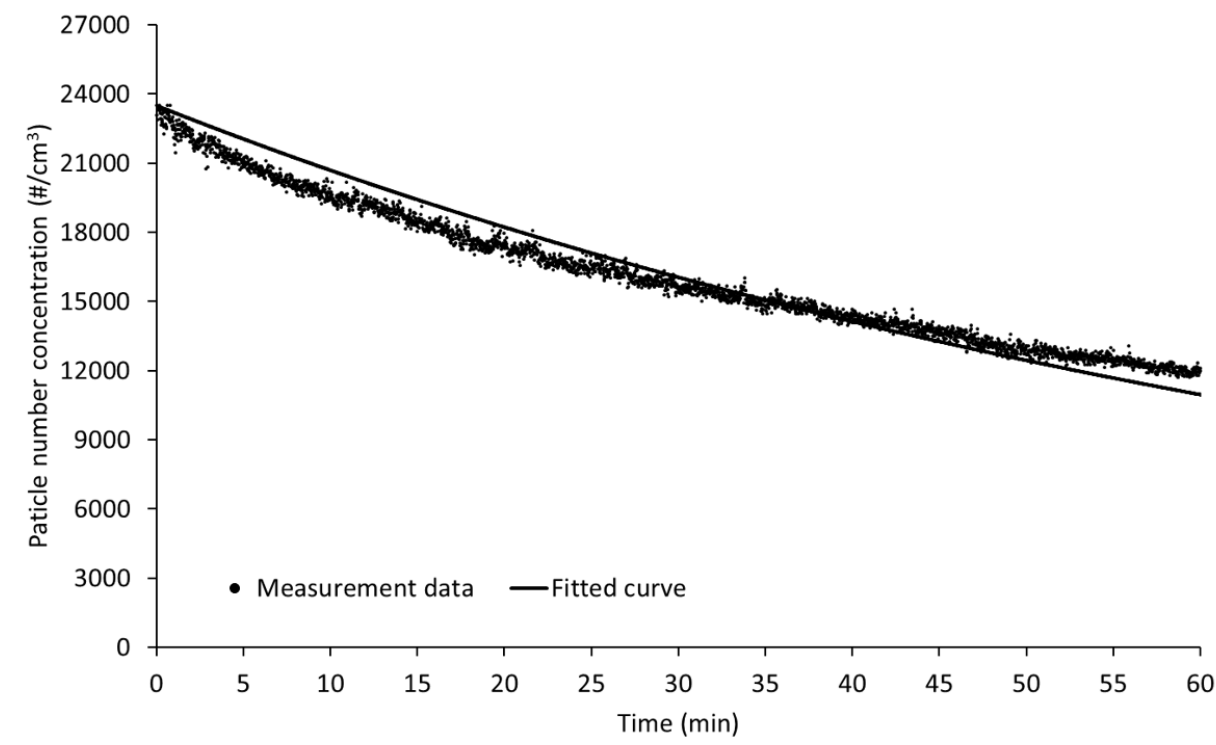

Fig. 2. Experimental measurement and curve fitting on the natural decay of the particle number concentration in the tested classroom.

The term $S$ in Eq. (8) represents the emission rate of all indoor particle sources. During the experimental measurements, eight occupants were brought into the classroom and became the emission source. The eight occupants included one professor in his 70 s and seven students between 20-35 years old, who were all wearing face masks during the experiment. $S$ was then calculated as the product of the total occupant number and particle emission rate per occupant. The particle concentration at the start of the experiment was measured to be $850 \mathrm{\#} \mathrm{cm}^{-3}$ with only the AHU operating at a flow rate of $0.047 \mathrm{~m}^{3} \mathrm{~s}^{-1}$. The average outdoor ambient concentration of $6742 \mathrm{\#} \mathrm{cm}^{-3}$ was recorded, and the wall-loss coefficient was the same as the value calculated in the previous step. By fitting the measurement data with Eq. (8), it was found that each occupant generated particles with an emission rate of $10 \mathrm{\#} \mathrm{s}^{-1}$, as shown in Fig. 3. This value is in good agreement with the measured data reported by He et al. (2021) on the aerosol generation rate by an individual breathing or speaking. The fitted curve has an $R^{2}$ value of 0.499 , as indicated by the figure. The concentration increase in Fig. 3 was caused by not only the occupants but also

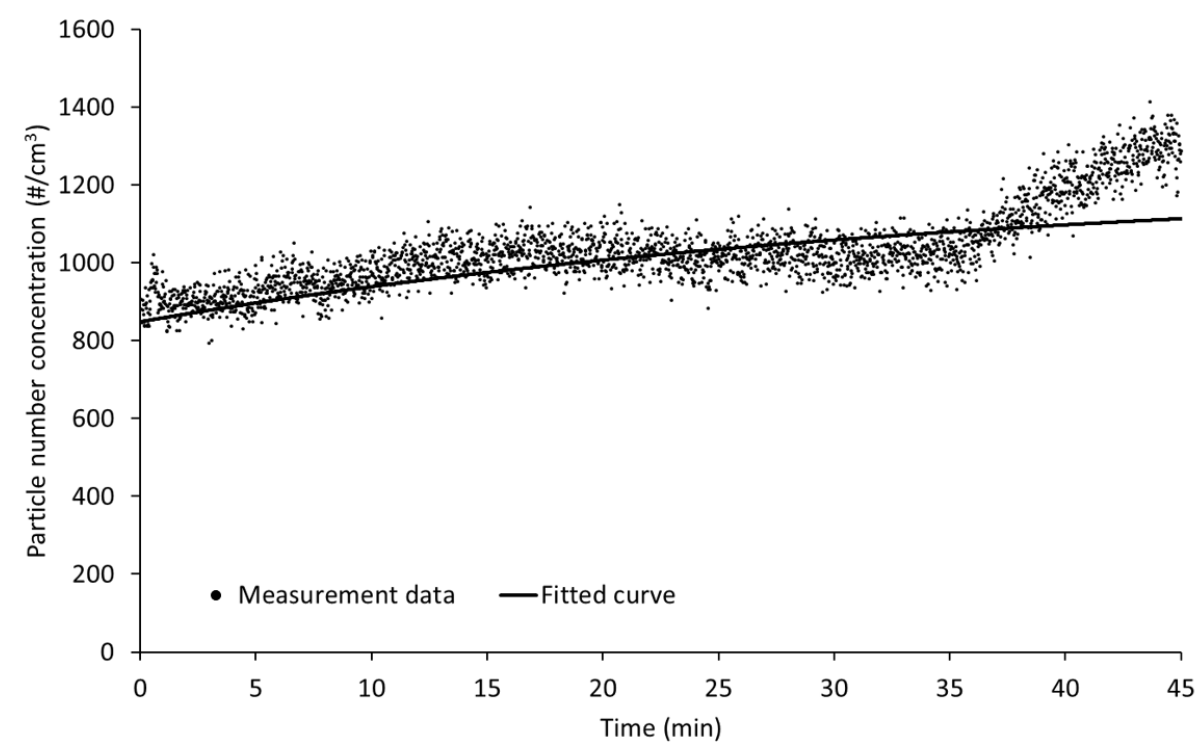

Fig. 3. Measured particle number concentration and the corresponding curve fitting when there were eight occupants in the classroom. 
the AHU system which introduced some ambient particles into the classroom. To recapitulate what has been presented in this section, the empirical wall-loss coefficient was found to be 1.71

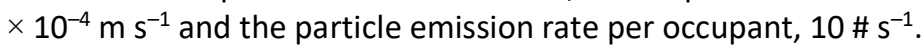

\section{RESULTS AND DISCUSSION}

To compare the particle concentration decay predicted by the analytical model with experimental data, measurements were conducted under four experimental conditions. Two system flow rates of $0.142 \mathrm{~m}^{3} \mathrm{~s}^{-1}$ (300 CFM) and $0.047 \mathrm{~m}^{3} \mathrm{~s}^{-1}$ (100 CFM) were applied for the AHU. Filters with different efficiency classes were installed in the ventilation systems. MERV 15 filters with an efficiency of 0.9 were equipped in the AHU, while MERV 13 (efficiency of 0.7 ) or MERV 8 (efficiency of 0.17 ) were used for the FCU. As the majority of the particles are in the $0.3-1.0 \mu \mathrm{m}$ size range used to determine a filter's MERV value, results in that size range were chosen here (ANSI/ASHRAE, 2012). For each experiment, the FCU system was running at its full capacity with a flow rate of $0.354 \mathrm{~m}^{3} \mathrm{~s}^{-1}$ (750 CFM). Before all the measurements, an atomizer was applied to generate particles with $1 \% \mathrm{NaCl}$ solution, while during the measurements, all particle sources were turned off.

The particle number concentrations for each condition shown in "Results" are normalized by the corresponding initial concentration measured during the experiments. Fig. 4 shows the normalized particle number concentration as a function of time for the four experimental conditions with both the measurement data and analytical results plotted. By increasing the AHU flow rate or upgrading the filter's efficiency class in the FCU, the particle concentration in the classroom achieves higher decay rates. In general, the analytical model follows the decaying trends of the measurement data reasonably well. The discrepancy between the two can be due to the well-mixed assumption of the analytical model, impact of local mixing caused by airflows in the classroom, effect of additional surface area from indoor furniture on particle deposition, and inaccuracy of sizedependent input parameters in the analytical equation such as the filtration efficiencies. At $15 \mathrm{~min}$, the particle concentration is reduced by $86.9 \%, 79.9 \%, 65.5 \%$, and $50.0 \%$ for the four scenarios, as predicted by the analytical model.

To evaluate the ability of the AHU system itself in controlling the indoor contaminant levels, the analytical model was applied to calculate the normalized particle number concentrations with only the AHU operating. Two system flow rates of $0.047 \mathrm{~m}^{3} \mathrm{~s}^{-1}(100 \mathrm{CFM})$ and $0.142 \mathrm{~m}^{3} \mathrm{~s}^{-1}$ (300 CFM) were chosen. For each flow rate, the three filter efficiency classes of MERV 8/13/15 were applied. The initial indoor particle concentration and outdoor ambient concentration were

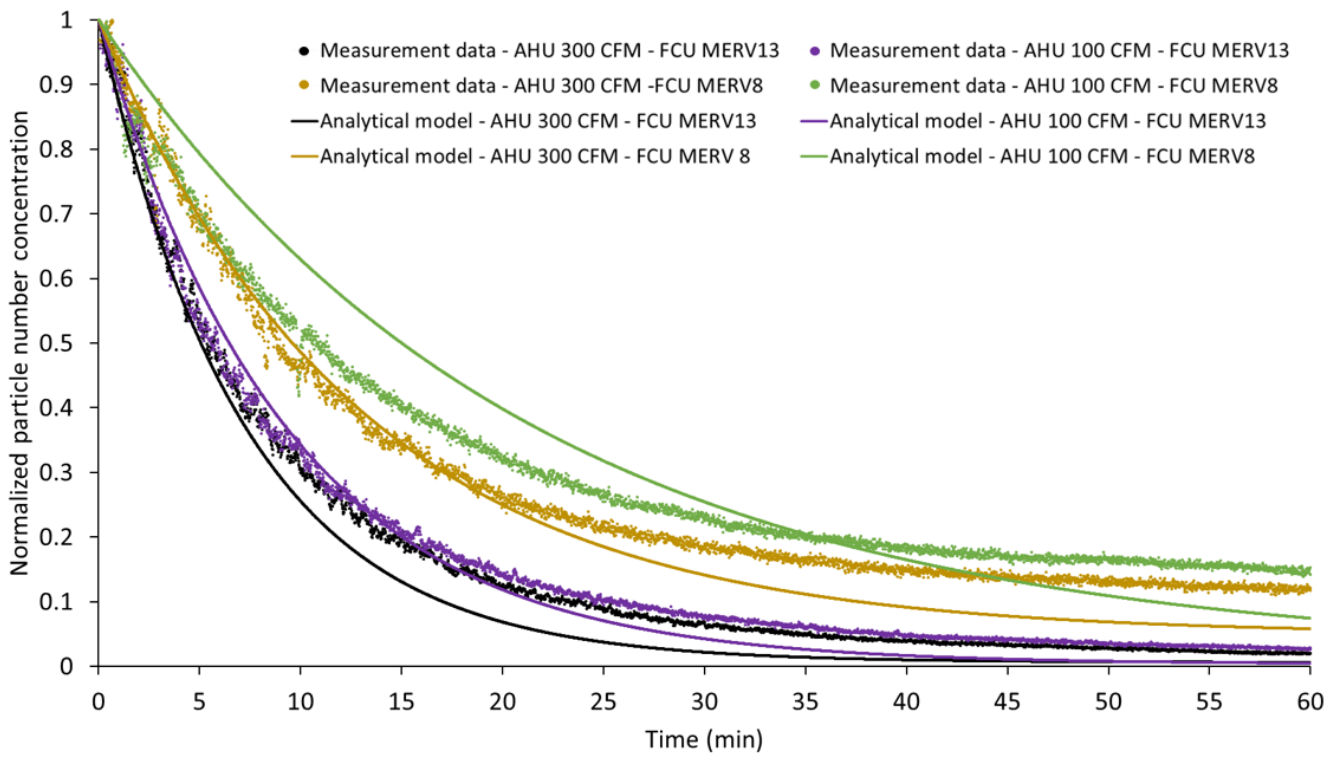

Fig. 4. Comparison of the normalized particle number concentration decay curves between the experimental data and analytical results. 
assumed to be $10,000 \mathrm{\#} \mathrm{cm}^{-3}$ and $4,000 \mathrm{\#} \mathrm{cm}^{-3}$, respectively. Results calculated by the analytical model are plotted in Fig. 5. The solid curves represent cases with the flow rate of $0.047 \mathrm{~m}^{3} \mathrm{~s}^{-1}$ (100 CFM), while the dashed curves indicate cases with the higher flow rate of $0.142 \mathrm{~m}^{3} \mathrm{~s}^{-1}(300 \mathrm{CFM})$. With the MERV 15 filter equipped and a flow rate of $0.142 \mathrm{~m}^{3} \mathrm{~s}^{-1}$ (300 CFM), the AHU system can reduce the indoor particle number concentration by $56.5 \%$ in the first $15 \mathrm{~min}$ of operation. This is the normal operating condition of the ventilation system of a typical modern classroom at the University of Minnesota.

Fig. 6 indicates the normalized particle number concentration when only the FCU operates under six different conditions. Two system flow rates of $0.177 \mathrm{~m}^{3} \mathrm{~s}^{-1}(375 \mathrm{CFM})$ and $0.354 \mathrm{~m}^{3} \mathrm{~s}^{-1}$ (750 CFM) were considered, as shown by the solid and dashed curves, respectively. The results illustrate that by upgrading the ventilation system with a higher filter efficiency class, the FCU performance can be significantly enhanced. For instance, at a system flow rate of $0.354 \mathrm{~m}^{3} \mathrm{~s}^{-1}$

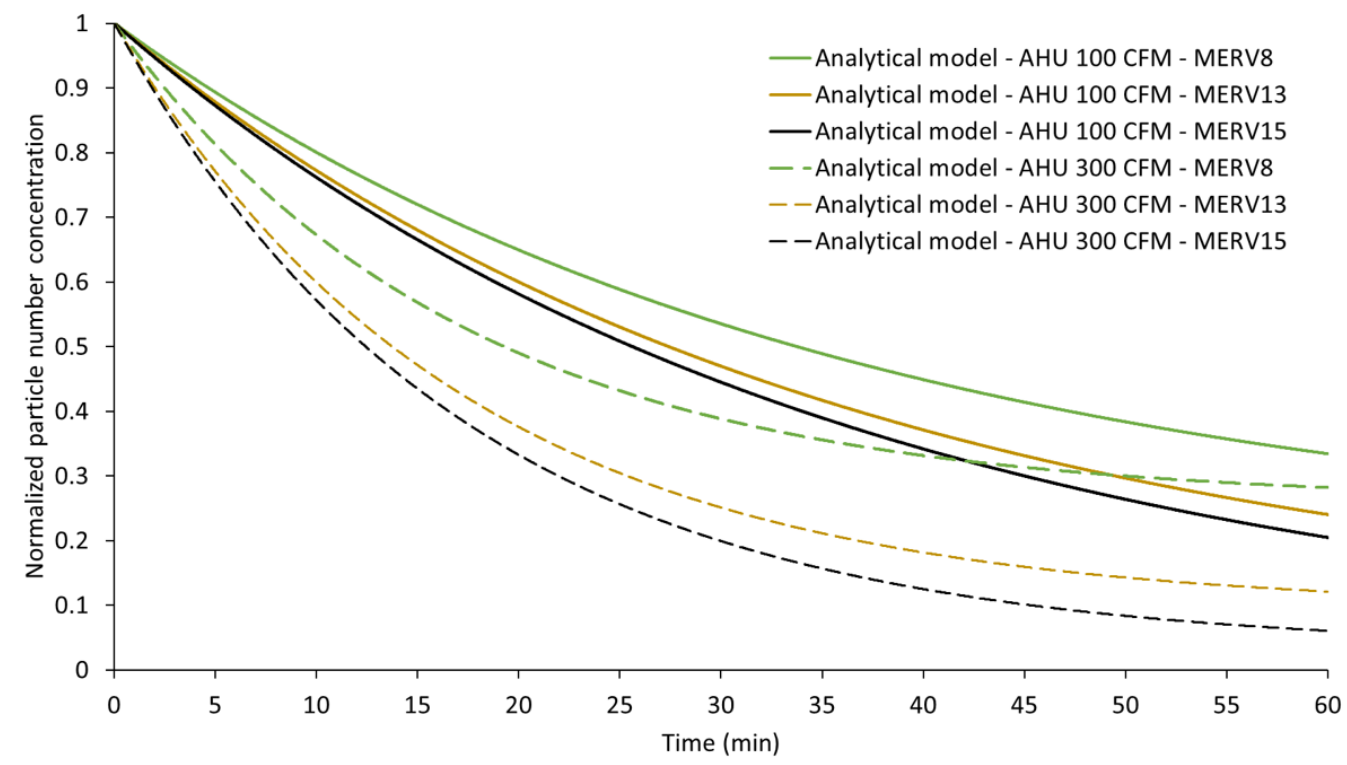

Fig. 5. Normalized particle number concentration when only the AHU is operating with different filter efficiency classes.

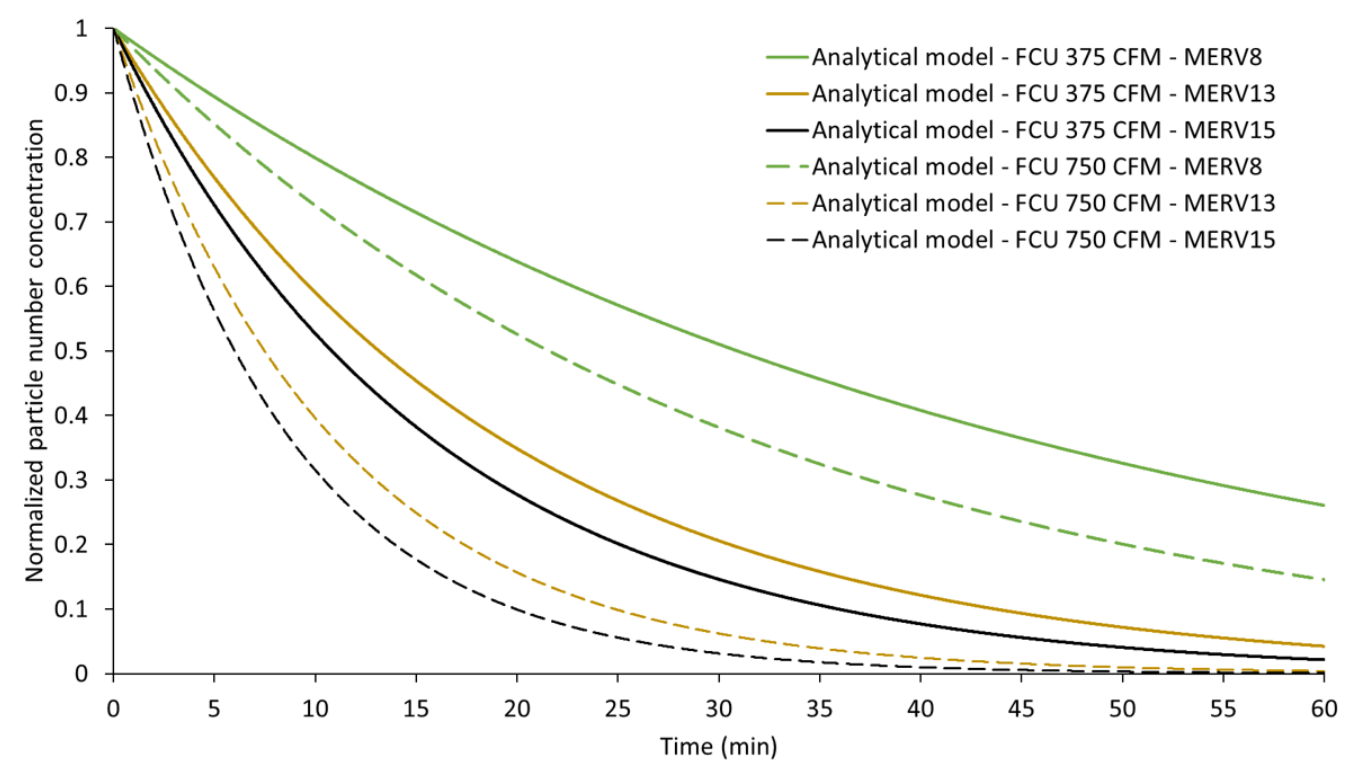

Fig. 6. Normalized particle number concentration when only the FCU is operating with different filter efficiency classes. 


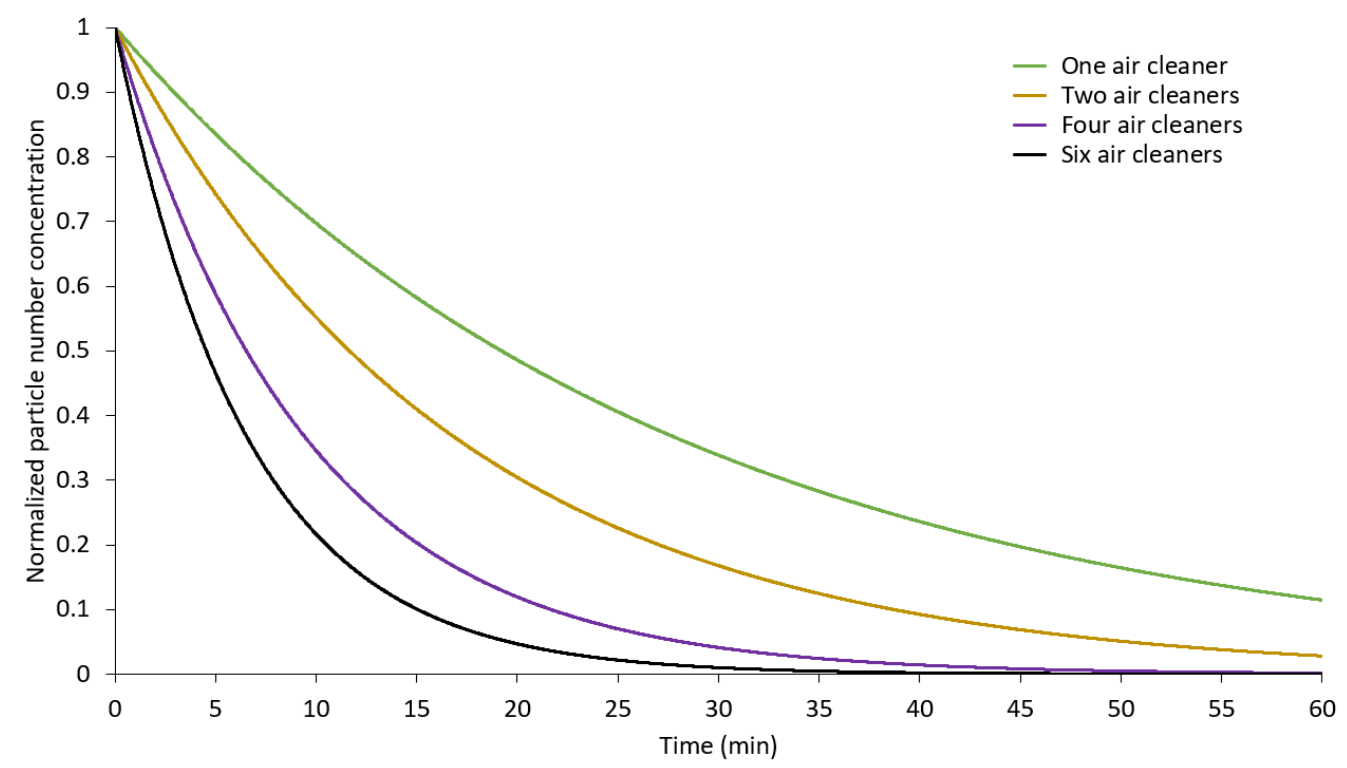

Fig. 7. Normalized particle number concentration with different numbers of IACs operating.

(750 CFM), if the MERV 8 filter is replaced by the MERV 13 filter, particle removal percentage at 15 min will be changed from $38.2 \%$ to $75.1 \%$. Currently, the university classrooms are mostly equipped with MERV 8 filters in the FCU systems. It is suggested that these filters should be upgraded to MERV 13 so that the FCU system performance can be improved substantially.

Some old classrooms in the university do not have an AHU or FCU system, in which case IACs are required for particulate contaminant removal. Fig. 7 gives the analytical results for the particle concentration decay while different numbers of IACs are running in the classroom. The flow rate of each air cleaner was assumed to be $0.0755 \mathrm{~m}^{3} \mathrm{~s}^{-1}$ (160 CFM), which is the maximum flow rate of the Oreck Airlnstinct air purifier (Model AIR108), a common device at the university. An indoor air cleaner is always equipped with a high-efficiency particulate air (HEPA) filter, which has a filtration efficiency close to 1.0. Here we used an efficiency of 0.96 which is based on our experimental evaluation of these air cleaners. As shown in Fig. 7, the particle concentration can be reduced by $41.8 \%, 59.0 \%, 79.7 \%$, and $90.0 \%$ for the one-cleaner, two-cleaner, four-cleaner, and six-cleaner scenarios, respectively. This result illustrates that even if a classroom does not have its AHU or FCU system, the indoor particle concentration can still be reduced fairly quickly by introducing enough air cleaners.

\section{SUMMARY}

We have developed an analytical model for estimating the particle number concentration decay in indoor classrooms and residences that factors in the filtration efficiencies of AHUs and FCUs, effects of indoor air cleaners, particle deposition on walls, and particle emission from occupants. Based on experimental measurements, we determined the wall-loss coefficient, $k_{\mathrm{w}}$, and the particle generation rate per occupant to be $1.71 \times 10^{-4} \mathrm{~m} \mathrm{~s}^{-1}$ and $10 \mathrm{\#} \mathrm{s}^{-1}$, respectively, and found good agreement between the modeling predictions and the observation data for four scenarios, validating the derived analytical model. We then employed the model to analyze the change in the indoor particle concentration under different operating conditions.

One limitation of this model is its assumption that the AHU supplies only outdoor air, whereas in the real world, an AHU typically supplies a mixture of outdoor air and recirculated air from other classrooms in the same building-a scenario that should be addressed in the future. In addition, although Eq. (8) can be used for any airborne contaminant, several of its parameters depend on the particle size, including the filtration efficiencies, wall-loss coefficient, and emission source term, which confines the application of the model to a specific range of aerodynamic diameters, regardless of the particles' morphology or chemical composition. Furthermore, the 
model estimates the total particle number concentration by integrating the results over a range of particle sizes rather than examining any size in particular. In our study, we selected a size range of $2.5 \mathrm{~nm}-2 \mu \mathrm{m}$, which corresponds to the limits of the instrument used to experimentally measure the wall-loss coefficient and the occupant emission rate. However, as the analytical results change with the outdoor particle size distribution, filter efficiency, and source particle size distribution, the model's integrated prediction varies according to the particle-size-dependent parameters. This issue can be addressed in a future study on a size-dependent analytical model.

The analytical model has been integrated with a graphical user interface and made freely available as a web application at cfr.umn.edu under the Particle Decay Model tab. The user should input the following parameters: the dimensions of the classroom; flow rates of the AHU, FCU, and IAC; filter classes for the AHU, FCU, and IAC; initial indoor particle number concentration; outdoor ambient particle number concentration; and total number of occupants. Because the efficiency of a filter is a function of the particle size and the face velocity, these values must be correct in order to produce accurate results. The user can also compare the particle concentration decay rates in up to three scenarios by checking "Case 1," "Case 2," and, if necessary, "Case 3." As the conditions from Case 1 are automatically applied to Case 2 and Case 3, only the changed variable(s) must be updated, e.g., substituting "MERV 8" in Case 1 with "MERV 13" in Case 2 to assess the effect of a different filter class. By offering a valuable practical tool for facility engineers to evaluate the indoor particle concentration reduction rates on school campuses, we believe that our work will be highly beneficial to controlling air quality in classrooms.

\section{NOMENCLATURE}

$A_{s} \quad$ internal surface area of the classroom, $\mathrm{m}^{2}$.

a integration coefficient.

$k_{\mathrm{w}} \quad$ wall-loss coefficient, $\mathrm{m} \mathrm{s}^{-1}$.

$M \quad$ integration coefficient.

$N \quad$ particle number concentration, $\# \mathrm{~cm}^{-3}$.

$N_{0} \quad$ initial indoor particle number concentration, $\# \mathrm{~cm}^{-3}$.

$Q \quad$ flow rate, $\mathrm{m}^{3} \mathrm{~s}^{-1}$.

$S$ indoor particle emission rate, $\# \mathrm{~s}^{-1}$.

$t$ time, s.

$V \quad$ volume of the classroom, $\mathrm{m}^{3}$.

\section{Greek}

$\eta \quad$ particulate filtration efficiency.

\section{Subscripts}

AHU air handling unit.

a ambient (outdoor).

dp a specific particle size, $\mu \mathrm{m}$.

FCU fan coil unit.

IAC indoor air cleaner.

\section{ACKNOWLEDGMENTS}

The authors would like to thank the members of the Center for Filtration Research: 3M Corp.; Applied Materials, Inc.; BASF Corp.; Boeing Co.; Corning Inc.; China Yancheng Environmental Protection Science and Technology City; Cummins Filtration Inc.; Donaldson Co., Inc.; Entegris, Inc.; Ford Motor Co.; Guangxi Wat Yuan Filtration System Co., Ltd.; LG Electronics Co.; MSP Corp.; Parker Hannifin; Samsung Electronics Co., Ltd.; Shengda Filtration Technology Co., Ltd.; TSI Inc.; W. L. Gore \& Associates, Inc.; Shigematsu Works Co., Ltd.; and the affiliate member National Institute for Occupational Safety and Health (NIOSH). 


\section{REFERENCES}

Adeniran, J.A., Araromi, D.O., Yusuf, R.O., Jimoda, L.A., Oke, E.O., Sonibare, J.A. (2019). Analytical modeling of human exposure from short-term point source releases of aerosols from household spray products. Sci. Technol. Built Environ. 25, 83-90. https://doi.org/10.1080/237 44731.2018.1499383

Alshitawi, M.S., Awbi, H.B. (2011). Measurement and prediction of the effect of students' activities on airborne particulate concentration in a classroom. HVAC\&R Res. 17, 446-464. https://doi.org/10.1080/10789669.2011.583708

Amirav, I., Newhouse, M.T. (2020). Transmission of coronavirus by nebulizer: A serious, underappreciated risk. CMAJ 192, E346. https://doi.org/10.1503/cmaj.75066

ANSI/ASHRAE Standard 52.2 (2012). Method of testing general ventilation air-cleaning devices for removal efficiency by particle size. American Society of Heating, Refrigerating and Air Conditioning Engineers, Atlanta, GA. http://www.techstreet.com/products/1848989

Asadi, S., Bouvier, N., Wexler, A.S., Ristenpart, W.D. (2020). The coronavirus pandemic and aerosols: Does COVID-19 transmit via expiratory particles? Aerosol Sci. Technol. 54, 635-638. https://doi.org/10.1080/02786826.2020.1749229

Bartik, A.W., Bertrand, M., Cullen, Z., Glaeser, E.L., Luca, M., Stanton, C. (2020). The impact of COVID-19 on small business outcomes and expectations. Proc. Natl. Acad. Sci. U.S.A. 117, 17656-17666. https://doi.org/10.1073/pnas.2006991117

Bennett, J., Davy, P., Trompetter, B., Wang, Y., Pierse, N., Boulic, M., Phipps, R., HowdenChapman, P. (2019). Sources of indoor air pollution at a New Zealand urban primary school; a case study. Atmos. Pollut. Res. 10, 435-444. https://doi.org/10.1016/j.apr.2018.09.006

Bhangar, S., Huffman, J.A., Nazaroff, W.W. (2014). Size-resolved fluorescent biological aerosol particle concentrations and occupant emissions in a university classroom. Indoor Air 24, 604617. https://doi.org/10.1111/ina.12111

Borro, L., Mazzei, L., Raponi, M., Piscitelli, P., Miani, A., Secinaro, A. (2020). The role of air conditioning in the diffusion of Sars-CoV-2 in indoor environments: A first computational fluid dynamic model, based on investigations performed at the Vatican State Children's Hospital. Environ. Res. 193, 110343. https://doi.org/10.1016/j.envres.2020.110343

Crump, J.G., Seinfeld, J.H. (1981). Turbulent deposition and gravitational sedimentation of an aerosol in a vessel of arbitrary shape. J. Aerosol Sci. 12, 405-415. https://doi.org/10.1016/ 0021-8502(81)90036-7

Crump, J.G., Flagan, R.C., Seinfeld, J.H. (1982). Particle wall loss rates in vessels. Aerosol Sci. Technol. 2, 303-309. https://doi.org/10.1080/02786828308958636

Donthu, N., Gustafsson, A. (2020). Effects of COVID-19 on business and research. J. Bus. Res. 117, 284-289. https://doi.org/10.1016/j.jbusres.2020.06.008

Fazli, T., Zeng, Y., Stephens, B. (2019). Fine and ultrafine particle removal efficiency of new residential HVAC filters. Indoor Air 29, 656-669. https://doi.org/10.1111/ina.12566

Fotou, G.P., Pratsinis, S.E. (1993). A correlation for particle wall losses by diffusion in dilution chambers. Aerosol Sci. Technol. 18, 213-218. https://doi.org/10.1080/02786829308959596

Fuoco, F.C., Stabile, L., Buonanno, G., Trassiera, C.V., Massimo, A., Russi, A., Mazaheri, M., Morawska, L., Andrade, A. (2015). Indoor air quality in naturally ventilated Italian classrooms. Atmosphere 6, 1652-1675. https://doi.org/10.3390/atmos6111652

Ganesh, H.S., Fritz, H.E., Edgar, T.F., Novoselac, A., Baldea, M. (2019). A model-based dynamic optimization strategy for control of indoor air pollutants. Energy Build. 195, 168-179. https://doi.org/10.1016/j.enbuild.2019.04.022

Gheziel, A., Hanini, S., Mohamedi, B., Ararem, A. (2017). Particle dispersion modeling in ventilated room using artificial neural network. Nucl. Sci. Tech. 28, 5. https://doi.org/10.1007/s41365016-0159-6

Guo, H., Morawska, L., He, C., Gilbert, D. (2008). Impact of ventilation scenario on air exchange rates and on indoor particle number concentrations in an air-conditioned classroom. Atmos. Environ. 42, 757-768. https://doi.org/10.1016/j.atmosenv.2007.09.070

He, R., Gao, L., Trifonov, M., Hong, J. (2021). Aerosol generation from different wind instruments. J. Aerosol Sci. 151, 105669. https://doi.org/10.1016/j.jaerosci.2020.105669 
Holmberg, S., Chen, Q. (2003). Air flow and particle control with different ventilation systems in a classroom. Indoor Air 13, 200-204. https://doi.org/10.1034/j.1600-0668.2003.00186.x

Holmberg, S., Li, Y. (1998). Modelling of the indoor environment - Particle dispersion and deposition. Indoor Air 8, 113-122. https://doi.org/10.1111/j.1600-0668.1998.t01-2-00006.x

Howard-Reed, C., Wallace, L.A., Emmerich, S.J. (2003). Effect of ventilation systems and air filters on decay rates of particles produced by indoor sources in an occupied townhouse. Atmos. Environ. 37, 5295-5306. https://doi.org/10.1016/j.atmosenv.2003.09.012

Johnson, D.L., Lynch, R.A., Floyd, E.L., Wang, J., Bartels, J.N. (2018). Indoor air quality in classrooms: Environmental measures and effective ventilation rate modeling in urban elementary schools. Build. Environ. 136, 185-197. https://doi.org/10.1016/j.buildenv.2018. 03.040

Kim, J., Park, S., Kim, H., Yeo, M.S. (2019). Emission characterization of size-resolved particles in a pre-school classroom in relation to children's activities. Indoor Built Environ. 28, 659-676. https://doi.org/10.1177/1420326X17707565

Kuehn, T.H., Ramsey, J.W., Threlkeld, J.L. (1998). Thermal environmental engineering. Pearson, London, U.K.

Laiman, R., He, C., Mazaheri, M., Clifford, S., Salimi, F., Crilley, L.R., Mokhtar, M.A.M., Morawska, L. (2014). Characteristics of ultrafine particle sources and deposition rates in primary school classrooms. Atmos. Environ. 94, 28-35. https://doi.org/10.1016/j.atmosenv.2014.05.013

Liu, W., You, R., Chen, C. (2019). Modeling transient particle transport by fast fluid dynamics with the Markov chain method. Build. Simul. 12, 881-889. https://doi.org/10.1007/s12273-0190513-9

Mehmood, K., Saifullah, Iqbal, M., Abrar, M.M. (2020). Can exposure to PM2.5 particles increase the incidence of coronavirus disease 2019 (COVID-19)? Sci. Total Environ. 741, 140441. https://doi.org/10.1016/j.scitotenv.2020.140441

Mehta, P., McAuley, D.F., Brown, M., Sanchez, E., Tattersall, R.S., Manson, J.J. (2020). COVID-19: Consider cytokine storm syndromes and immunosuppression. Lancet 395, 1033-1034. https://doi.org/10.1016/S0140-6736(20)30628-0

Mullen, N.A., Bhangar, S., Hering, S.V., Kreisberg, N.M., Nazaroff, W.W. (2011). Ultrafine particle concentrations and exposures in six elementary school classrooms in northern California. Indoor Air 21, 77-87. https://doi.org/10.1111/j.1600-0668.2010.00690.x

Mutlu, M. (2020). Numerical investigation of indoor air quality in a floor heated room with different air change rates. Build. Simul. 13, 1063-1075. https://doi.org/10.1007/s12273-0200683-5

Nazaroff, W.W., Cass, G.R. (1989). Mathematical modeling of indoor aerosol dynamics. Environ. Sci. Technol. 23, 157-166. https://doi.org/10.1021/es00179a003

Nicola, M., Alsafi, Z., Sohrabi, C., Kerwan, A., Al-Jabir, A., losifidis, C., Agha, M., Agha, R. (2020). The socio-economic implications of the coronavirus (COVID-19): A review. Int. J. Surg. 78, 185193. https://doi.org/10.1016/j.ijsu.2020.04.018

Nsir, K., Sartelet, K., Bresson, R., Genon, L.M. (2019). Three-dimensional computational fluid dynamics modelling of sodium oxide aerosol atmospheric dispersion from indoor sodium fire. J. Aerosol Sci. 137, 105433. https://doi.org/10.1016/j.jaerosci.2019.105433

Park, J., Jang, Y., Ahn, Y., Cheong, S., Lee, J. (2008). Estimation of appropriate capacity of ventilation system based on the air infiltration rate in Korean classrooms. J. Mech. Sci. Technol. 22, 788-797. https://doi.org/10.1007/s12206-008-0111-8

Pui, D.Y.H., Qi, C., Stanley, N., Oberdörster, G., Maynard, A. (2008). Recirculating air filtration significantly reduces exposure to airborne nanoparticles. Environ. Health Perspect. 116, 863866. https://doi.org/10.1289/ehp.11169

Qian, J., Hospodsky, D., Yamamoto, N., Nazaroff, W.W., Peccia, J. (2012). Size-resolved emission rates of airborne bacteria and fungi in an occupied classroom. Indoor Air 22, 339-351. https://doi.org/10.1111/j.1600-0668.2012.00769.x

Ren, J., Wade, M., Corsi, R.L., Novoselac, A. (2020). Particulate matter in mechanically ventilated high school classrooms. Build. Environ. 184, 106986. https://doi.org/10.1016/j.buildenv.2020. 106986

Sajjadi, H., Salmanzadeh, M., Ahmadi, G., Jafari, S. (2017). Turbulent indoor airflow simulation using hybrid LES/RANS model utilizing Lattice Boltzmann method. Comput. Fluids 150, 66-73. https://doi.org/10.1016/j.compfluid.2017.03.028 
Shereen, M.A., Khan, S., Kazmi, A., Bashir, N., Siddique, R. (2020). COVID-19 infection: Emergence, transmission, and characteristics of human coronaviruses. J. Adv. Res. 24, 91-98. https://doi.org/10.1016/j.jare.2020.03.005

Stabile, L., Dell'Isola, M., Frattolillo, A., Massimo, A., Russi, A. (2016). Effect of natural ventilation and manual airing on indoor air quality in naturally ventilated Italian classrooms. Build. Environ. 98, 180-189. https://doi.org/10.1016/j.buildenv.2016.01.009

Stabile, L., Massimo, A., Canale, L., Russi, A., Andrade, A., Dell'Isola, M. (2019). The effect of ventilation strategies on indoor air quality and energy consumptions in classrooms. Buildings 9, 10. https://doi.org/10.3390/buildings9050110

Tian, L., Lin, Z., Wang, Q., Liu, J. (2009). Numerical investigation of indoor aerosol particle dispersion under stratum ventilation and under displacement ventilation. Indoor Built Environ. 18, 360-375. https://doi.org/10.1177/1420326X09337335

Tippayawong, N., Khuntong, P. (2007). Model prediction of indoor particle concentrations in a public school classroom. J. Chin. Inst. Eng. 30, 1077-1083. https://doi.org/10.1080/02533839. 2007.9671334

van Doremalen, N., Bushmaker, T., Morris, D.H., Holbrook, M.G., Gamble, A., Williamson, B.N., Tamin, A., Harcourt, J.L., Thornburg, N.J., Gerber, S.I., Lloyd-Smith, J.O., de Wit, E., Munster, V.J. (2020). Aerosol and surface stability of SARS-CoV-2 as compared with SARS-CoV-1. N. Engl. J. Med. 382, 1564-1567. https://doi.org/10.1056/NEJMc2004973

Vuorinen, V., Aarnio, M., Alava, M., Alopaeus, V., Atanasova, N., Auvinen, M., Balasubramanian, N., Bordbar, H., Erästö, P., Grande, R., Hayward, N., Hellsten, A., Hostikka, S., Hokkanen, J., Kaario, O., Karvinen, A., Kivistö, I., Korhonen, M., Kosonen, R., Kuusela, J., et al. (2020). Modelling aerosol transport and virus exposure with numerical simulations in relation to SARS-CoV-2 transmission by inhalation indoors. Saf. Sci. 130, 104866. https://doi.org/10.1016/j.ssci.2020. 104866

Wei, W., Ramalho, O., Malingre, L., Sivanantham, S., Little, J.C., Mandin, C. (2019). Machine learning and statistical models for predicting indoor air quality. Indoor Air 29, 704-726. https://doi.org/10.1111/ina.12580

Weichenthal, S., Dufresne, A., Infante-Rivard, C., Joseph, L. (2008). Characterizing and predicting ultrafine particle counts in Canadian classrooms during the winter months: Model development and evaluation. Environ. Res. 106, 349-360. https://doi.org/10.1016/j.envres.2007.08.013

Zheng, Y.Y., Ma, Y.T., Zhang, J.Y., Xie, X. (2020). COVID-19 and the cardiovascular system. Nat. Rev. Cardiol. 17, 259-260. https://doi.org/10.1038/s41569-020-0360-5 